\title{
Isocyanate Reduction by Epoxide Substitution of Alcohols for Polyurethane Bioelastomer Synthesis
}

\author{
Arnold A. Lubguban, ${ }^{1}$ Zuleica R. Lozada, ${ }^{1}$ Yuan-Chan Tu, ${ }^{2}$ Hongyu Fan, ${ }^{2}$ Fu-Hung Hsieh, ${ }^{2}$ \\ and Galen J. Suppes ${ }^{1}$ \\ ${ }^{1}$ Department of Chemical Engineering, University of Missouri-Columbia, W2033 Lafferre Hall, Columbia, MO 65211, USA \\ ${ }^{2}$ Department of Biological Engineering, University of Missouri-Columbia, 248 AE Building, Columbia, MO 65211, USA
}

Correspondence should be addressed to Galen J. Suppes, suppesg@missouri.edu

Received 10 June 2011; Accepted 23 July 2011

Academic Editor: Cyrille Boyer

Copyright (C) 2011 Arnold A. Lubguban et al. This is an open access article distributed under the Creative Commons Attribution License, which permits unrestricted use, distribution, and reproduction in any medium, provided the original work is properly cited.

\begin{abstract}
A phosphate ester-forming reaction was carried out by mixing epoxidized soybean oil with up to $1.5 \% o$-phosphoric acid. In situ oligomerization took effect almost instantly producing a clear, homogeneous, highly viscous, and a low-acid product with a high average functionality. The resulting epoxide was used as a reactant for urethane bioelastomer synthesis and evaluated for rigid foam formulation. Results have shown that with a number of catalysts tested phosphoric acid significantly enhances a solvent-free oxirane ring cleavage and polymerization of the epoxidized soybean oil via phosphate-ester formation at room temperature. The resulting phosphoric acid-catalyzed epoxide-based bioelastomer showed an $80 \%$ decrease in extractable content and increased tensile strength at the same isocyanate loading relative to the noncatalyzed epoxide. The oligomerized epoxidized soybean oil materials exhibited ASTM hydroxyl values $40 \%$ less than the nonoligomerized starting material which translates to reduced isocyanate loadings in urethane applications.
\end{abstract}

\section{Introduction}

Polyurethane elastomers and industrial foams manufacturing rely significantly on fossil fuels and their derivatives as major reactants for the production of polyols. Nonrenewable resources are rapidly being exhausted, therefore, a growing worldwide research effort is focused on the understanding and using renewable resources to reduce dependence on petroleum-derived materials and to develop innovative technologies and competitive industrial products. Vegetable oils such as soybean oil (SBO) are increasingly replacing petroleum-derived products owing to its environmentfriendly, biodegradable, and noncorrosive properties [1-3].

Although SBO-based polyols have shown promising results in the production of urethane-formulated products ranging from elastomers to flexible foams [3-5], replacement of substantial portions of polyol and isocyanate with soybean oil-derived epoxides is economically significant. SBO-derived epoxides which include epoxidized soybean oil (ESBO) and bodied ESBO are intermediates in much of the chemistry to create soy-based polyols [4, 6-8], and so they are less expensive than many soy-based polyols. High reactivity through cleavage of the oxirane ring makes epoxides very versatile both as chemical intermediates and as end product. Epoxides are able to directly react with water to diols, with carboxylic acids to ester alcohols, and with alcohols to ether alcohols [9]. Moreover, epoxides have been reported to react with and partially displace isocyanate in urethane mixtures $[6,10,11]$; hence, urethane formulations with increased bio-based content can be developed. A multifunctional monomer containing one or more epoxide moieties may thus to some extent displace alcohol and isocyanate in the regular urethane formulation.

Phosphoric acid $\left(o-\mathrm{H}_{3} \mathrm{PO}_{4}\right)$ has been extensively used in the preparation of a series of soybean oil phosphate esters for rigid polyurethanes, coatings, surfactants, and antiwear additives [1, 2, 12-15]. Guo et al. [2] reported that soy polyols having tunable hydroxyl content and phosphate ester functionality are possible by controlling the type and amount of polar solvent and phosphoric acid content added to the 
reactants. The authors claimed that phosphoric acid does not only catalyze ring-opening reaction of ESBO with water but also chemically combine to become part of the polyol product. Much of the work done to produce soybean oil phosphate ester polyols used water and significant amount of polar solvents to obtain high hydroxyl functionality while keeping the final acid values low $[1,2,14,15]$.

The main objectives of this work were to (1) develop catalyst formulations to specifically promote solventless epoxide reaction in epoxide-substituted polyol (ESP) and effectively replace substantial amounts of the petroleum-based polyol and (2) develop urethane bioelastomer formulations using epoxides or ESP to reduce the total isocyanate content. Acid, hydroxyl, oxirane values, and viscosity of the epoxides or ESP were measured to evaluate the effect of $o-\mathrm{H}_{3} \mathrm{PO}_{4}$ on ringopening hydrolysis and oligomerization of the monomers.

\section{Materials}

2.1. Synthesis of Epoxide-Substituted Polyol (ESP). Ortho$\mathrm{H}_{3} \mathrm{PO}_{4} 85 \%$ aqueous from Fisher Scientific, ESBO (Vikoflex 7170) $7.0 \%$ oxirane from Arkema (King of Prussia, Pa, USA), polymeric methylene diphenyl diisocyanate or pMDI (PAPI 27) $31.4 \mathrm{wt} \% \mathrm{NCO}$ from Dow Chemical (Midland, Mïch, USA), and castor oil (CO) from Alnor Oil (Valley Stream, NY, USA). Full epoxidized soybean oil was reacted with $0.5 \%-2.0 \% \quad o-\mathrm{H}_{3} \mathrm{PO}_{4}$ added dropwise in a beaker under vigorous mechanical stirring at room temperature. A homogeneous and highly viscous product is obtained after mixing for $5 \mathrm{~min}$. The schematic of this reaction is shown in Figure 1. The next step was the preparation of a series of ESPs by varying the amount of epoxide (noncatalyzed or $o-\mathrm{H}_{3} \mathrm{PO}_{4}$-catalyzed ESBO) in castor oil. This was done by moderately mixing the epoxide and castor oil at room temperature until a homogeneous ESP is obtained.

2.2. Preparation of Urethane Bioelastomers. Two types of bioelastomers were prepared: (1) ESPs using only $0.5 \%$ by weight $o-\mathrm{H}_{3} \mathrm{PO}_{4}$ with noncatalyzed ESP as control, and (2) acid-catalyzed ESBO using $0.5-1.5 \%$ by weight $o-\mathrm{H}_{3} \mathrm{PO}_{4}$ without castor oil and noncatalyzed ESBO as control. The preparation procedure of ESP bioelastomer consists of the following steps: (1) mixing $5.0 \mathrm{~g}$ ESP and $2.5 \mathrm{~g}$ pMDI in a $50 \mathrm{~mL}$ beaker on a hotplate equipped with stirrer (moderate stirring at room temperature was employed to obtain uniform phase and consistency and also avoid bubbles formation), (2) placing the samples in a $7 \mathrm{~cm} \times 11 \mathrm{~cm}$ rectangular plastic mold and degassed for $10 \mathrm{~min}$ at $45^{\circ} \mathrm{C}$ vacuum oven to get rid of $\mathrm{CO}_{2}$, air trapped, or gases evolved during reaction, and (3) postcuring samples for about $48 \mathrm{~h}$ at $45^{\circ} \mathrm{C}[3]$ in an oven with no vacuum applied. Extractability of unreacted oil phase of the finely cut samples was measured after $48 \mathrm{~h}$ of curing. The second type of bioelastomers was prepared the same way, but the amount of $o-\mathrm{H}_{3} \mathrm{PO}_{4}$ was varied $(0.5,1.0,1.5 \%)$, and no alcohol source (castor oil) was added. Polymeric MDI was added at $10-30 \%$ by weight of the acid-reacted ESBO. After postcure, dumbbell-shaped specimens were cut from the bioelastomer samples using an ASTM D638 Type V cutter.
2.3. Characterization of ESPs and Bioelastomers. Hydroxyl values of ESPs were determined according to an American Oil Chemists' Society (AOCS) Official Method Tx 1a-66 (1997). Acid numbers (mgKOH/g sample) of all reaction products were evaluated according to the AOCS official method (AOCS Te 1a-64, 1997). Epoxy content of the ESP samples was measured according to AOCS-official method (AOCS Cd 9-57, 1997). The dynamic viscosities (cP measured at $20^{\circ} \mathrm{C}$ ) of the ESPs were determined using a Model RS100 Rheometer (Haake, Paramus, NJ, USA). The synthesized epoxides and ESPs displayed non-Newtonian behavior like many other polymer solutions as shown by their nonlinear shear stress and strain rate relationship plotted on the instrument program's data manager. Gardner color index was evaluated according to ASTM D1544-04 (Reapproved, 2010). Tensile properties of the bioelastomers were determined by a TA. HDi Texture Analyzer (Texture Technologies Corp., Scarsdale, NY, USA) following ASTM Procedure D 882-10. The test specimens were airtight sealed and conditioned at $23 \pm 2^{\circ} \mathrm{C}\left(73.4 \pm 3.6^{\circ} \mathrm{F}\right)$ and $50 \pm$ $5 \%$ relative humidity for not less than $40 \mathrm{~h}$ prior to test. The initial gauge length of the sample was $7.62 \mathrm{~mm}$, and the crosshead speeds were 12.5 and $50 \mathrm{~mm} / \mathrm{min}$ depending on the percent elongation at break. DSC measurements were carried out on a TA Instruments (New Castle, Del, USA) DSC Q100. All DSC measurements were performed following the ASTM E 1356-08 standard. The specimens were airtightsealed prior to testing. About $10 \mathrm{mg}$ of the bioelastomer samples were heated at a rate of $10^{\circ} \mathrm{C} / \mathrm{min}$ from -60 to $100^{\circ} \mathrm{C}$ under dry nitrogen gas atmosphere.

The functional groups of the noncatalyzed and $o$ $\mathrm{H}_{3} \mathrm{PO}_{4}$-catalyzed ESBO bioelastomers were characterized by an attenuated total reflectance-Fourier transform infrared (ATR-FTIR) spectroscopy using Thermo Scientific Nicolet 4700 (Thermo Electron Corp., Madison, Wis, USA) equipped with Smart Detectors and multiple spectral range. The sample was pressed against an ATR diamond to have a good contact. A total of 64 scans from $4000-400 \mathrm{~cm}^{-1}$ wavenumber range were obtained at a resolution of $4 \mathrm{~cm}^{-1}$. The functional groups present in the control bioelastomer (noncatalyzed with $o-\mathrm{H}_{3} \mathrm{PO}_{4}$ ), with peak intensities corresponding to the wavenumbers, were epoxy at $824 \mathrm{~cm}^{-1}$ (high intensity), epoxy at $920 \mathrm{~cm}^{-1}$ (present), phosphate ester at $1020 \mathrm{~cm}^{-1}$ (absent), urethane bonds at $1730 \mathrm{~cm}^{-1}$ (present), 2-oxazolidone at $1760 \mathrm{~cm}^{-1}$ (absent), NCO groups at $2280 \mathrm{~cm}^{-1}$ (present), and urethane bonds at $3340 \mathrm{~cm}^{-1}$ (high intensity). In comparison, the functionality groups present in the sample bioelastomer (catalyzed with $O$ $\mathrm{H}_{3} \mathrm{PO}_{4}$ ) were epoxy at $824 \mathrm{~cm}^{-1}$ (low intensity), epoxy at $920 \mathrm{~cm}^{-1}$ (present), phosphate ester at $1020 \mathrm{~cm}^{-1}$ (high intensity), urethane bonds at $1730 \mathrm{~cm}^{-1}$ (present), 2-oxazolidone at $1760 \mathrm{~cm}^{-1}$ (absent), NCO groups at $2280 \mathrm{~cm}^{-1}$ (present), and urethane bonds at $3340 \mathrm{~cm}^{-1}$ (low intensity).

The differentiation in structures of both unreacted and acid-reacted ESBO were confirmed by ${ }^{13} \mathrm{C}-\mathrm{NMR}$ (Bruker DRX $\left.500 \mathrm{MHz}, \mathrm{CDCl}_{3}\right)$. Both samples exhibited the spectra of epoxy groups present in the $\delta 56.9-58.5 \mathrm{ppm}$ region. The unreacted ESBO was showed a slightly higher intensity in this region indicating more epoxy groups present compared with 

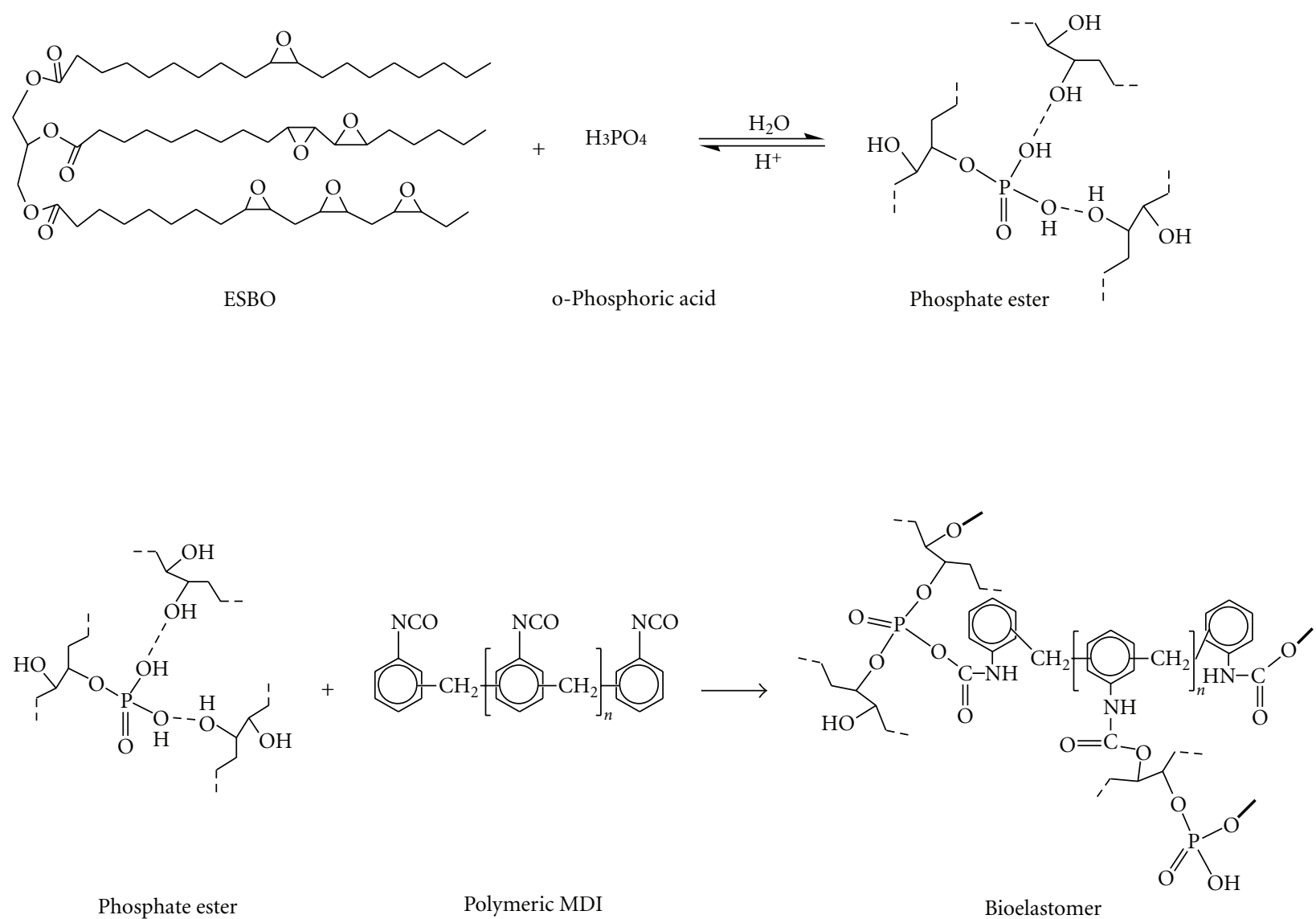

FIgURE 1: Overall schematic representation of phosphate ester and subsequent bioelastomer formation.

the acid-reacted sample. A ${ }^{1} \mathrm{H}-\mathrm{NMR}$ analyses of the samples showed no significant difference in chemical shifts.

2.4. Extractability Test and Catalyst Evaluation. A singlestep unreacted oil-phase extraction method was used to determine the extent of polymer cross-linking between pMDI and ESP. Polymeric MDI and the sample ESP were well mixed in a small disposable aluminum pan. The resulting elastomeric wafer product was left to cure for $24 \mathrm{~h}$ in a convection oven for $48 \mathrm{~h}$ at $45^{\circ} \mathrm{C}$ for ESP bioelastomers. The cured wafer samples were then cooled to room temperature and cut into thin sheets for unreacted oil extraction. About a gram of each cut sample was soaked with occasional stirring in a $1: 4$ by volume $n$-hexane-cyclohexanol solution for 15 min after which the mixture is filtered. Both permeate and retentate were dried in a vacuum oven at $110^{\circ} \mathrm{C}$ for $2 \mathrm{~h}$. The percentage of unreacted oil phase was calculated by mass balance. This test is a straightforward reaction of epoxides and pMDI. This basic polymerization reaction is described elsewhere [16].

Different organic and inorganic chemicals (acids, bases, alcohols, polymers, surfactants, metal salts, amides, amines, etc.) were initially evaluated according to their catalytic effect on the reaction between ESBO and pMDI. Table 1 showed a list of the catalysts and their corresponding catalytic performance based on the extractability test described above.
About $0.5 \%$ by weight of each catalyst was added to ESBO and mixed well at room temperature. The catalyzed ESBO was reacted with pMDI in a $2: 1$ mass ratio, and the resulting PU mixture was then cured in a $140^{\circ} \mathrm{C}$ convection oven for $24 \mathrm{~h}$. The PU wafers were tested for unreacted oil phase. Lower extractable content correlates with better catalytic performance for the PU-forming reaction. Phosphoric acid showed the lowest extractable content and was, therefore, used to produce the epoxide-substituted polyols.

\section{Results and Discussion}

In this work, a urethane bioelastomer formulation is studied following the epoxide-substituted polyol (ESP) and polymeric diphenylmethane diisocyanate (pMDI) reaction, including physicochemical characterization of the elastomer products. Catalysts were evaluated to specifically promote epoxide reaction. Ortho-phosphoric acid lowered the oxirane concentration of the epoxide even at room temperature with no solvents added. A simplified scheme of the process is shown in Figure 2.

ESP reacted in an open glass vessel with the acid catalyst added dropwise until a homogeneous phase is obtained. Proper mixing was crucial in attaining a uniformly catalyzed product. After the completion of reaction, pMDI was added 
TABLE 1: Catalysts evaluation by extractable content method. A sample elastomeric wafer was a mixture of catalyzed ESBO (0.5\% catalyst) and pMDI at $2: 1$ mass ratio then cured at $140^{\circ} \mathrm{C} / 24 \mathrm{~h}$ in a convection oven.

\begin{tabular}{|c|c|c|}
\hline Sample & Catalyst used & Extracted oil phase, $\%$ \\
\hline Control & None & 16.0 \\
\hline 1 & $\mathrm{~K}_{2} \mathrm{HPO}_{4}$ & 17.2 \\
\hline 2 & Tin(II) 2-Ethylhexanoate & 10.0 \\
\hline 3 & Triethanolamine & 15.1 \\
\hline 4 & $o$-Phosphoric acid & 2.85 \\
\hline 5 & Glycerol & 15.6 \\
\hline 6 & 1,4-diazabicyclo[2.2.2] octane (DABCO) 8154 & 21.1 \\
\hline 7 & Polycat SA-1 & 22.6 \\
\hline 8 & DABCO BL-17 & 21.6 \\
\hline 9 & Propylamine & 18.9 \\
\hline 10 & Propionamide & 17.9 \\
\hline 11 & Octadecanamide & 19.5 \\
\hline 12 & N-Methyl-N-nitroso- $p$-toluenesulfonamide (Diazald) & 14.0 \\
\hline 13 & N-Bromo-succinimide & 15.4 \\
\hline 14 & N,N-Dimethylformamide & 15.9 \\
\hline 15 & $\mathrm{KH}_{2} \mathrm{PO}_{4}$ & 14.4 \\
\hline 16 & Calcium carbonate & 15.1 \\
\hline 17 & $n$-Butanol & 15.6 \\
\hline 18 & Methanol & 16.2 \\
\hline 19 & Methanol + sulfuric acid & 17.0 \\
\hline 20 & Perfluoric acid-PTF prepolymer & 13.8 \\
\hline 21 & Cobalt acetate & 15.2 \\
\hline 22 & Phthalic acid & 13.1 \\
\hline 23 & Acetic acid & 19.8 \\
\hline 24. & Formic acid & 11.3 \\
\hline 25 & $p$-Toluenesulfonic acid & 11.0 \\
\hline 26 & Titanocene dichloride & 10.2 \\
\hline 27 & 1-Naphthol-3,6-disulfonic acid disodium salt hydrate & 12.7 \\
\hline 28 & Phenylenediamine & 22.1 \\
\hline 29 & Potassium hydroxide & 41.5 \\
\hline 30 & Ammonium chloride & 16.1 \\
\hline 31 & Sulfuric acid & 15.2 \\
\hline
\end{tabular}

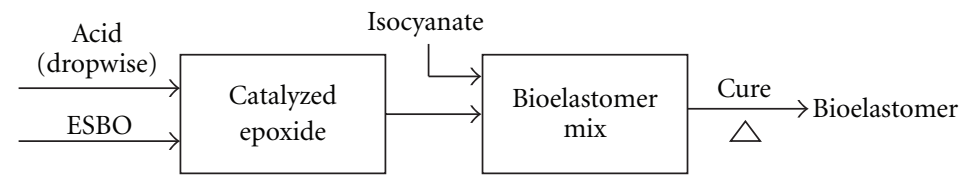

FIGURE 2: Schematic of bioelastomer synthesis. Oxirane opening reaction is performed at room temperature with constant stirring.

to ESP and the product degassed, then postcured in a convection oven. The postcured bioelastomer products displayed a range of physical properties from viscous and tacky to hard and brittle. Variations in the elastomer properties are attributed mainly to the isocyanate index used and hydroxyl equivalent weight of the $\operatorname{ESP}[7,17,18]$.

3.1. Extractability for Evaluation of Catalysts. An extractability analysis method was established in our previous work [19] to evaluate the reactivity of the polyol products with the polymeric MDI. The test determined the percentage of the unreacted oil phase in the elastomer. Low extractability is believed to correlate with high cross-linking, whereas high extractability is believed to correlate with the presence of nonfunctional or single-functional components in the B-side (alcohol side) of the urethane formulation.

In this study, the extractability method was used to evaluate the effect of different catalysts added in epoxidized soybean oil for promoting reaction with polymeric MDI. A lower extractable content value indicates higher cross- 
linking and better catalyst performance. Table 1 shows the extractability values of samples using different catalysts. While presented as catalysts, in some instances, the materials may participate in reaction.

More than 30 catalysts were evaluated as shown in Table 1. About half-promoted minor increases in reactivity with pMDI as shown in their extractable content. Phosphoric acid showed the lowest extractable content at $2.85 \%$ followed by a metal-based catalyst Tin (II) 2-ethylhexanoate at $10.0 \%$. The former was the catalyst of choice owing to its effect in the reactivity of epoxide or ESP with pMDI.

3.2. Mixing of Epoxide and Alcohol. Two mixing sequences were performed to investigate any changes in properties of the final ESP. In the first sequence, ESBO was made to react with $o-\mathrm{H}_{3} \mathrm{PO}_{4}$ separately before castor oil, was added. The other sequence was performed by mixing ESBO, castor oil and $o-\mathrm{H}_{3} \mathrm{PO}_{4}$ simultaneously. All reactions were performed at room temperature. The chemical properties of the final ESPs are summarized in Table 2.

Based on Table 2 results, there were no significant changes in the chemical properties of the final ESPs using different mixing sequences; therefore, the alcohol did not significantly interfere in the phosphate-epoxy ring reaction. Under the conditions of the reaction, the $o-\mathrm{H}_{3} \mathrm{PO}_{4}$ is believed to react directly with the oxirane group as shown in Figure 1 causing an increase in viscosity and decrease in the oxirane oxygen concentration. Slight increases in hydroxyl values are attributed to the increasing $o-\mathrm{H}_{3} \mathrm{PO}_{4}$ percentages where $o$ $\mathrm{H}_{3} \mathrm{PO}_{4}$ reacts to from an alcohol.

3.3. Extractability of ESPs. The schematic representation of the reaction of ESP/phosphate esters with pMDI is shown in Figure 1. For ESPs with higher alcohol concentration, it is expected that the unreacted oil extractability is lower because the hydroxyl groups of castor oil readily react with the NCOfunctional group of pMDI forming cross-linked urethane polymer network. The effect of catalysis and reaction of ESBO with $o-\mathrm{H}_{3} \mathrm{PO}_{4}$ is more pronounced at mass fractions between 0.5 to 1.0 ESBO in castor oil as shown in Figure 3.

With no alcohol loading, an increase from $4.1 \%$ (catalyzed) to $18.6 \%$ (noncatalyzed) unreacted oil phase is observed which suggests that the extent of ESP-pMDI reaction can be increased by increasing the amount of $o-\mathrm{H}_{3} \mathrm{PO}_{4}$. Lower extractability can be obtained by either increasing the alcohol loading in the bioelastomer mix or increasing the hydroxyl functionality (increase the hydroxyl equivalent weights at the same hydroxyl number) of the ESP which can be achieved by epoxy reaction with $o-\mathrm{H}_{3} \mathrm{PO}_{4}$.

The ASTM hydroxyl value of the polyol is used to calculate the amount of isocyanate needed to react with the polyol. The acid-catalyzed epoxide sample $\mathrm{C}$ in Table 3 shows an ASTM hydroxyl value of $240 \mathrm{mg} \mathrm{KOH} / \mathrm{g}$. The amount of isocyanate can be reduced to about $40 \%$ relative to the control with a hydroxyl value of $404 \mathrm{mg} \mathrm{KOH/g.} o-\mathrm{H}_{3} \mathrm{PO}_{4}-$ catalyzed ESBO presents the following potential advantages: increased polymeric network (high average functionality), displayed relatively higher tensile properties, and reduced

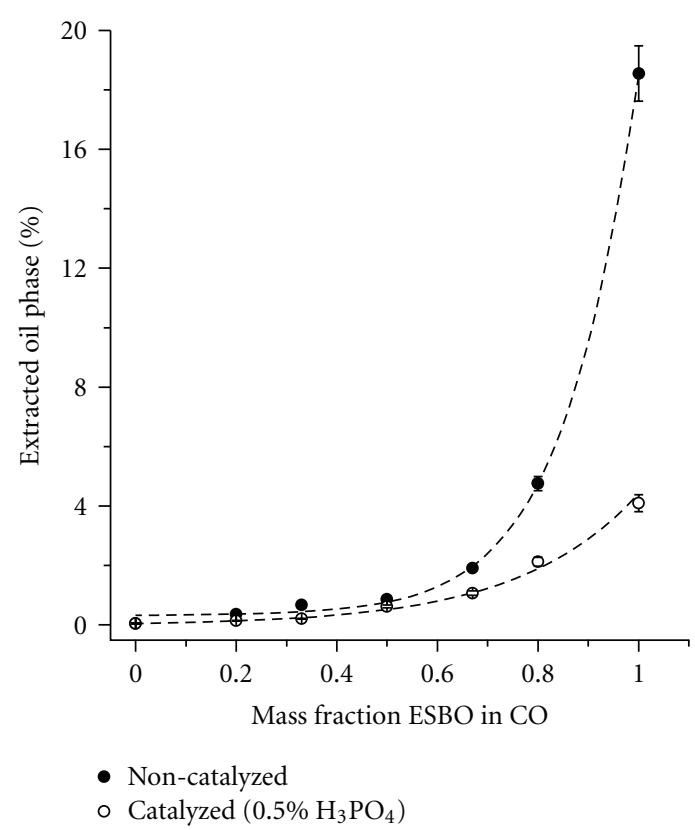

FIGURE 3: Extractability trend of urethane elastomers based on catalyzed and noncatalyzed ESBO. Urethane materials were formed from the reaction of ESPs (epoxide and castor oil) and polymeric MDI. Curing conditions were at $45^{\circ} \mathrm{C}$ for $48 \mathrm{~h}$ in a convection oven.

pMDI loading for both urethane bioelastomer and rigid foaming formulations.

3.4. Acid-Catalyzed Epoxide. Urethane bioelastomers were also prepared by reacting ESBO with $o-\mathrm{H}_{3} \mathrm{PO}_{4}$ without solvent or alcohol source. Table 3 presents the chemical properties of these samples with untreated ESBO as a control. A reduction of about $25 \%$ oxirane oxygen content was observed upon reacting ESBO with $1.5 \%$ phosphoric acid. Gelation was observed at $2.0 \%$ acid loading.

An increase in viscosity was observed as the amount of phosphoric acid added to ESBO was increased. Guo et al. [2] made the same observation and attributed the increase of viscosity and molecular weight to an increased tendency for oligomerization reaction due to higher acid concentration and the presence of increasing amount of higher phosphate esters and other reaction products. This established reaction which mainly involves epoxy ring opening forms polymeric or oligomeric species which results to an increase in molecular weight from the intermolecular phosphates di-and triester formation. Oligomerization through epoxy-epoxy and/or hydroxy-epoxy reaction is also highly possible in an acid catalysis of epoxy compounds. [1].

The epoxy ring-opening reaction was verified by FTIR with the untreated ESBO showing a more intense peak compared with acid-treated sample at wavenumber $824 \mathrm{~cm}^{-1}$, a characteristic of an epoxy signal. A steep increase in viscosity was also observed from $362 \mathrm{cP}$ for untreated ESBO to about $4000 \mathrm{cP}$ for the $1.5 \%$ acid-treated sample. This was indicative of the formation of phosphate esters which was verified by FTIR spectral intensity at wavenumber $1020 \mathrm{~cm}^{-1}$. This characteristic signal was not observed with the untreated ESBO sample. The acid number did not increase significantly 
TABLE 2: Chemical properties of ESPs using two different mixing sequences. The Gardner color indices of the samples range from1 to 3. All reacted samples composition: $1: 1$ by wt ESBO and CO. "Separate" indicates that acid reaction was done first before alcohol addition while "Simultaneous" that indicates acid and alcohol reactions were done at the same time.

\begin{tabular}{|c|c|c|c|c|}
\hline $\begin{array}{l}\% o-\mathrm{H}_{3} \mathrm{PO}_{4} \text { based on } \\
\text { ESBO }\end{array}$ & $\begin{array}{l}\text { Acid value, } \mathrm{mg} \mathrm{KOH} / \mathrm{g} \\
( \pm 0-5 \%)\end{array}$ & $\begin{array}{l}\text { Viscosity, cP } \\
( \pm 0.2-1 \%)\end{array}$ & $\begin{array}{l}\text { \%Oxirane oxygen } \\
\qquad( \pm 0.2-3 \%)\end{array}$ & $\begin{array}{c}\text { AOCS Hydroxyl value, } \\
\mathrm{mg} \mathrm{KOH} / \mathrm{g} \\
( \pm 2-4 \%)\end{array}$ \\
\hline \multicolumn{5}{|l|}{ Control } \\
\hline 0 & 1.54 & 434 & 3.44 & 84.10 \\
\hline \multicolumn{5}{|l|}{ Separate } \\
\hline 0.5 & 1.75 & 501 & 3.22 & 84.30 \\
\hline 1.0 & 1.65 & 665 & 3.12 & 89.56 \\
\hline 2.0 & 1.63 & 1240 & 2.69 & 95.36 \\
\hline \multicolumn{5}{|l|}{ Simultaneous } \\
\hline 0.5 & 1.90 & 507 & 3.30 & 87.70 \\
\hline 1.0 & 1.80 & 660 & 3.04 & 89.30 \\
\hline 2.0 & 1.90 & 1100 & 2.73 & 98.24 \\
\hline
\end{tabular}

TABLE 3: Chemical properties of $o-\mathrm{H}_{3} \mathrm{PO}_{4}$-reacted ESBO (at RT) without solvent or alcohol source.

\begin{tabular}{|c|c|c|c|c|c|c|}
\hline Sample code & $\begin{array}{c}\% o-\mathrm{H}_{3} \mathrm{PO}_{4} \\
\text { based on ESBO }\end{array}$ & $\begin{array}{c}\text { Acid value, mg } \\
\mathrm{KOH} / \mathrm{g} \\
( \pm 0-5 \%)\end{array}$ & $\begin{array}{c}\% \text { Oxirane } \\
\text { oxygen } \\
( \pm 0.2-3 \%)\end{array}$ & $\begin{array}{l}\text { AOCS Hydroxyl } \\
\text { value, mg } \\
\mathrm{KOH} / \mathrm{g}( \pm 2-4 \%)\end{array}$ & $\begin{array}{l}\text { ASTM Hydroxyl } \\
\text { Value, mg KOH/g } \\
\quad( \pm 0.3-5 \%)\end{array}$ & $\begin{array}{l}\text { Viscosity, cP } \\
( \pm 0.2-1 \%)\end{array}$ \\
\hline Control & 0 & $<0.20$ & 7.06 & 11.0 & 404 & 362 \\
\hline A & 0.5 & 0.77 & 6.77 & 23.0 & - & 559 \\
\hline B & 1.0 & 0.89 & 6.30 & 32.2 & - & 1020 \\
\hline $\mathrm{C}$ & 1.5 & 0.95 & 5.34 & 38.4 & 240 & 3950 \\
\hline
\end{tabular}

with increasing phosphoric acid loading. This indicates that the phosphate molecules completely react with the epoxy molecules up to at most $1.5 \%$ phosphoric acid loading.

Higher residual acidity is an undesirable polyol property as it competes with hydroxyls to react with isocyanates and consumes catalysts when these samples are further processed to produce bioelastomers and urethane foams. All samples maintained nonproblematic acid values less than 1.0. An increase in AOCS hydroxyl values from 11.0 to 38.4 was attributed mainly to an alcohol gain in the phosphate formation or partly on residual water from the aqueous $o$ $\mathrm{H}_{3} \mathrm{PO}_{4}$.

3.5. Bioelastomer Formation. The physicochemical properties of the bioelastomers synthesized from the treated epoxides in Table 3 are presented in Table 4. Urethane bond formation was verified by FTIR spectra at wavenumber $3340 \mathrm{~cm}^{-1}$ with a higher peak intensity observed with the bioelastomer synthesized from nontreated epoxide.

The greatest extent of cross-linking in elastomers will tend to occur when the A-side and B-side monomers are reacted in stoichiometric quantities. For urethane reactions, and especially for urethane reactions with epoxy moieties present, a complex network of reactions occurs, and reaction stoichiometry is not straightforward. However, even with this uncertainty, it is evident that at $10 \%$ pMDI there is an inadequate amount of isocyanate to completely react with the B-side alcohol and epoxy moieties. At 10\% pMDI loading, the bioelastomeric materials were too soft to be measured with its tensile properties. NCO concentration was less compared to the available alcohol/epoxy reacting groups which leave more unreacted soy-phosphate molecules.

At $30 \%$ pMDI, the isocyanate will tend to exhaust reaction with the alcohol moieties and undergo reactions that form undesirable brittle elastomers. At 30\% pMDI loading, bioelastomers were observed to be hard and brittle. This seemed to be the opposite of the $10 \%$ loading at the same curing temperature. Excess amounts of pMDI relative to the epoxy/alcohol groups may result in the formation of the hard segment composed of isocyanurate, biurets, and allophanates which would lead to brittleness and fragility of the urethane product. The $T_{g}$ values of the bioelastomers in Table 4 show a consistent trend; an increasing $T_{g}$ value as $\mathrm{OH} / \mathrm{NCO}$ molar ratio increases. Each bioelastomer sample shows one glass transition temperature which reflects a high degree of phase mixing between the hard segment and the soft-segment domains. Relatively higher combination of strength and strain performances was attained at about $25 \%$ pMDI loadings.

At the same pMDI loading, tensile strength increased with increasing mass percentage of phosphoric acid added to ESBO. The higher $o-\mathrm{H}_{3} \mathrm{PO}_{4}$ loading in ESBO led to increased viscosities which are associated with increased average molecular weights. The higher average molecular weight of the B-side monomer translates to more crosslinking and increased tensile strength.

At different pMDI loadings (e.g., samples 15C and 25A), the Young's modulus of the samples are comparatively 
TABLE 4: Tensile and thermal properties of bioelastomers from acid-catalyzed epoxides of Table 3. Bioelastomers were evaluated at $10 \%-30 \%$ by weight pMDI based on acid-treated ESBO.

\begin{tabular}{|c|c|c|c|c|c|}
\hline Sample code & Description & Strength at break, MPa & Strain at Break, \% & Young's modulus, MPa & $\mathrm{T}_{g}(\mathrm{DSC}),{ }^{\circ} \mathrm{C}$ \\
\hline $10 \mathrm{~A}$ & $\mathrm{~A}+10 \% \mathrm{pMDI}$ & & Material too soft & & - \\
\hline $10 \mathrm{~B}$ & $\mathrm{~B}+10 \%$ pMDI & & Material too soft & & - \\
\hline $10 \mathrm{C}$ & $\mathrm{C}+10 \% \mathrm{pMDI}$ & & Material too soft & & - \\
\hline $15 \mathrm{~A}$ & $\mathrm{~A}+15 \%$ pMDI & & Material too soft & & -10.2 \\
\hline $15 B$ & $\mathrm{~B}+15 \%$ pMDI & $0.29 \pm 0.01$ & $4.34 \pm 2.96$ & $0.22 \pm 0.03$ & -13.8 \\
\hline $15 \mathrm{C}$ & $\mathrm{C}+15 \%$ pMDI & $0.42 \pm 0.14$ & $5.10 \pm 2.89$ & $0.47 \pm 0.34$ & -17.4 \\
\hline $25 \mathrm{~A}$ & $\mathrm{~A}+25 \% \mathrm{pMDI}$ & $0.94 \pm 0.12$ & $9.00 \pm 1.54$ & $0.46 \pm 0.09$ & -11.5 \\
\hline $25 B$ & $\mathrm{~B}+25 \%$ pMDI & $1.32 \pm 0.14$ & $5.93 \pm 0.83$ & $0.95 \pm 0.07$ & -15.9 \\
\hline $25 \mathrm{C}$ & $\mathrm{C}+25 \% \mathrm{pMDI}$ & $1.47 \pm 0.12$ & $5.13 \pm 0.48$ & $2.04 \pm 0.36$ & -18.4 \\
\hline $30 \mathrm{~A}$ & $\mathrm{~A}+30 \%$ pMDI & & Material too brittle & & - \\
\hline $30 \mathrm{~B}$ & $\mathrm{~B}+30 \%$ pMDI & & Material too brittle & & - \\
\hline $30 \mathrm{C}$ & $\mathrm{C}+30 \% \mathrm{pMDI}$ & & Material too brittle & & - \\
\hline
\end{tabular}

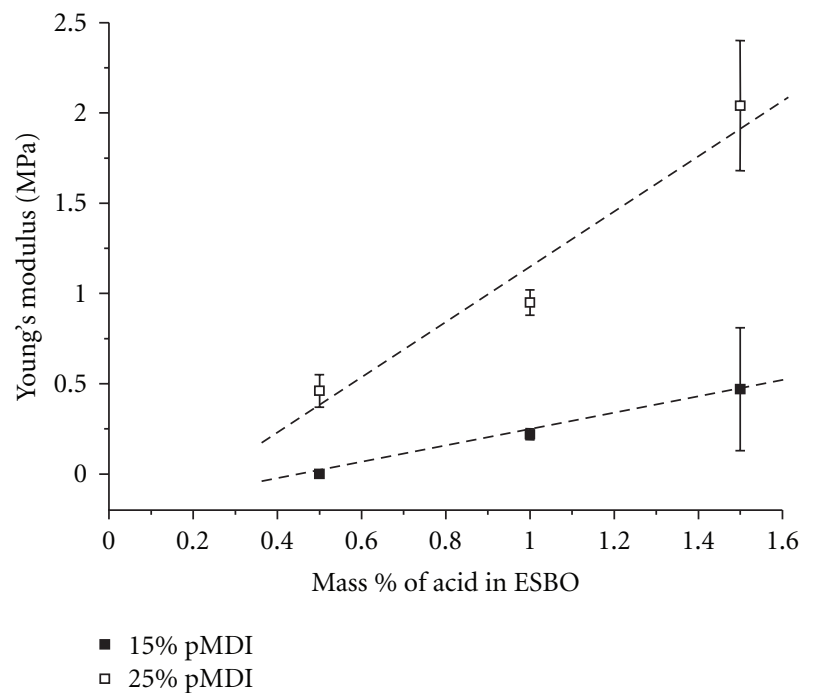

Figure 4: Effect of the amount of $o-\mathrm{H}_{3} \mathrm{PO}_{4}$ on Young's modulus of bioelastomers with $15 \%$ and $25 \%$ pMDI loading.

similar, which means that both samples have the same resistance to elastic deformation under load as shown in Figure 4.

\section{Conclusion}

Polymerized epoxidized soybean oil was synthesized by phosphate ester formation carried out by mixing epoxidized soybean oil with up to $1.5 \% o$-phosphoric acid at room temperature. The product was homogeneous, highly viscous, low acid, and with a high average functionality. The resulting phosphoric acid-catalyzed epoxide-based bioelastomer showed up to $80 \%$ decrease in extractable content and increased tensile strength at the same isocyanate loading relative to the noncatalyzed epoxide.

With the same catalyzed epoxide used as a B-side reactant in the rigid foam formulation, the amount of isocyanate can be reduced to about $40 \%$ compared with the noncatalyzed epoxide reactant. There was no significant increase in the hydroxyl number of the polyols, but its relatively lower extractable content indicates a higher hydroxyl equivalent weight due to its high molecular weight.

\section{Acknowledgments}

The authors thank Sangho Bok, Department of Electrical and Computer Engineering, University of Missouri, for recording FTIR spectra. Financial support from the United Soybean Board and the Consortium for Plant Biotechnology Research, Inc. is gratefully acknowledged.

\section{References}

[1] Y. Guo, V. M. Mannari, P. Patel, and J. L. Massingill, "Selfemulsifiable soybean oil phosphate ester polyols for low-VOC corrosion resistant coatings," Journal of Coatings Technology Research, vol. 3, no. 4, pp. 327-331, 2006.

[2] Y. Guo, J. H. Hardesty, V. M. Mannari, and J. L. Massingill, "Hydrolysis of epoxidized soybean oil in the presence of phosphoric acid," Journal of the American Oil Chemists' Society, vol. 84, no. 10, pp. 929-935, 2007.

[3] S. S. Narine, X. Kong, L. Bouzidi, and P. Sporns, "Physical properties of polyurethanes produced from polyols from seed oils: I. Elastomers," Journal of the American Oil Chemists' Society, vol. 84, no. 1, pp. 55-63, 2007.

[4] Y. C. Tu, P. Kiatsimkul, G. Suppes, and F. H. Hsieh, "Physical properties of water-blown rigid polyurethane foams from vegetable oil-based polyols," Journal of Applied Polymer Science, vol. 105, no. 2, pp. 453-459, 2007.

[5] L. Zhang, H. K. Jeon, J. Malsam, R. Herrington, and C. W. Macosko, "Substituting soybean oil-based polyol into polyurethane flexible foams," Polymer, vol. 48, no. 22, pp. 6656-6667, 2007.

[6] Y. C. Tu, G. J. Suppes, and F. H. Hsieh, "Water-blown rigid and flexible polyurethane foams containing epoxidized soybean oil triglycerides," Journal of Applied Polymer Science, vol. 109, no. 1, pp. 537-544, 2008.

[7] P. P. Kiatsimkul, G. J. Suppes, and W. R. Sutterlin, "Production of new soy-based polyols by enzyme hydrolysis of bodied soybean oil," Industrial Crops and Products, vol. 25, no. 2, pp. 202-209, 2007. 
[8] P. P. Kiatsimkul, G. J. Suppes, F. H. Hsieh, Z. Lozada, and Y. C. $\mathrm{Tu}$, "Preparation of high hydroxyl equivalent weight polyols from vegetable oils," Industrial Crops and Products, vol. 27, no. 3, pp. 257-264, 2008.

[9] G. Knothe and J. T. P. Derksen, Recent Developments in the Synthesis of Fatty Acid Derivatives, AOCS Press, Champaign, III, USA, 1999.

[10] T. I. Kadurina, V. A. Prokopenko, and S. I. Omelchenko, "Studies of interactions in oligomeric epoxy resin-isocyanate systems," European Polymer Journal, vol. 22, no. 11, pp. 865$870,1986$.

[11] T. I. Kadurina, V. A. Prokopenko, and S. I. Omelchenko, "Curing of epoxy oligomers by isocyanates," Polymer, vol. 33, no. 18, pp. 3858-3864, 1992.

[12] J. P. L. Dwan'Isa, A. K. Mohanty, M. Misra, L. T. Drzal, and M. Kazemizadeh, "Novel biobased polyurethanes synthesized from soybean phosphate ester polyols: thermomechanical properties Evaluations," Journal of Polymers and the Environment, vol. 11, no. 4, pp. 161-168, 2003.

[13] B. Zhong, C. Shaw, M. Rahim, and J. Massingill, "Novel coatings from soybean oil phosphate ester polyols," Journal of Coatings Technology, vol. 73, no. 915, pp. 53-57, 2001.

[14] R. B. Cracknell and A. J. Moore, "Polyether phosphate esters," US Patent Office, Patent No. 5,414,103, 1995.

[15] S. Sato, R. C. Bueno, and W. B. De Almeida, "Dimer and trimer acid esters from epoxidized compounds and methods for their preparation," US Patent Office, Patent No. 6,274,750, 2001.

[16] R. Herrington and K. Hock, Flexible Foams, The Dow Chemical Company, Midland, Mich, USA, 1997.

[17] M. Modesti and A. Lorenzetti, "Experimental method for evaluating isocyanate conversion and trimer formation in polyisocyanate-polyurethane foams," European Polymer Journal, vol. 37, no. 5, pp. 949-954, 2001.

[18] Huntsman International LLC, "Process for preparing a polyurethane material," European Patent Application, EP $1178061 \mathrm{~A} 1,2002$.

[19] A. A. Lubguban, Y. C. Tu, Z. R. Lozada, F. H. Hsieh, and G. J. Suppes, "Functionalization via glycerol transesterification of polymerized soybean oil," Journal of Applied Polymer Science, vol. 112, no. 1, pp. 19-27, 2009. 

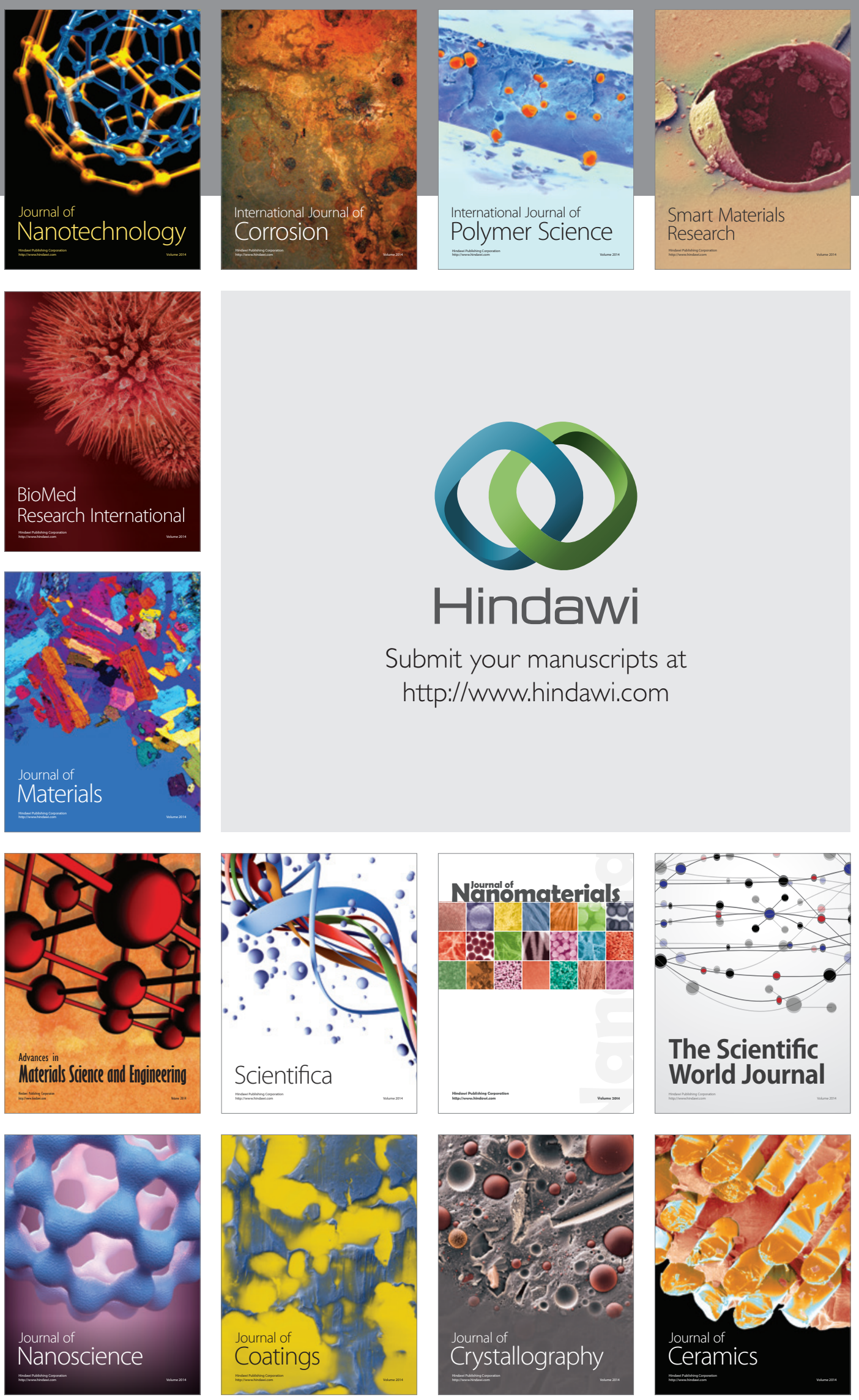

The Scientific World Journal

Submit your manuscripts at

http://www.hindawi.com

\section{World Journal}

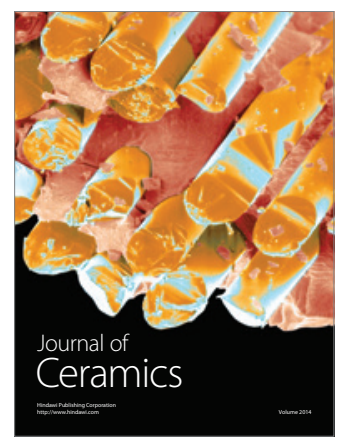

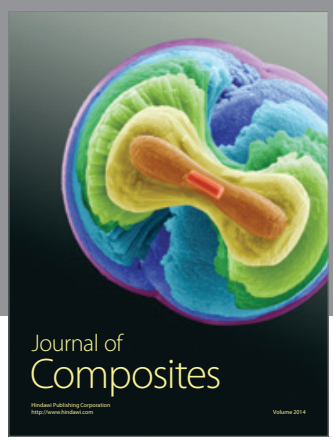
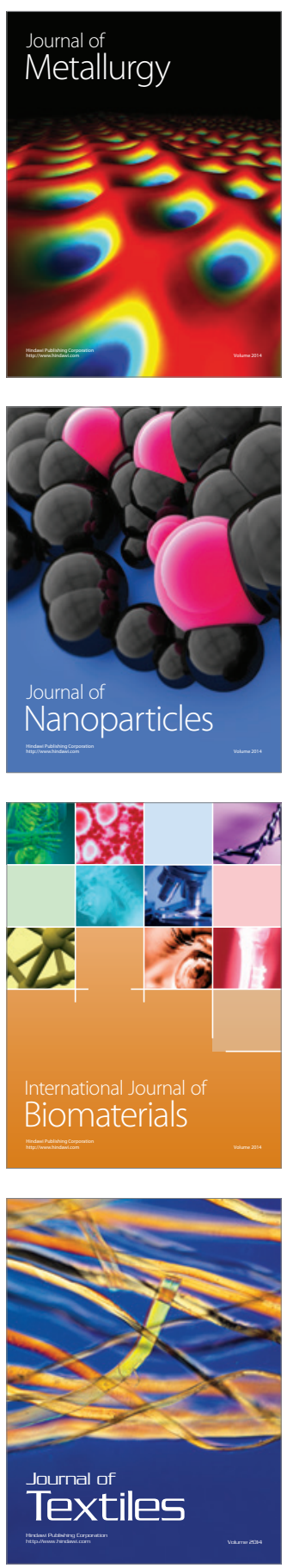